\title{
Global Economic Impacts of COVID 19 to Increase the Protection of Society By Using Thermal Imaging Cameras to Measure the Temperature of Human Body
}

\author{
Ladislav Mariš ${ }^{1, *}$, and Veronika Adamová ${ }^{1}$ \\ ${ }^{1}$ University of Zilina, Faculty of Security engineering, Department of Security Management, \\ Univerzitna 1, 01026 Zilina, Slovakia
}

\begin{abstract}
.
Research background: In 2020, a pandemic of COVID-19 has started. One of the symptoms is that a person has an elevated body temperature. One of the preventive measures against the spread of COVID-19 is the body temperature measuring. But this does not immediately mean, that person's elevated body temperature indicates the presence of COVID-19. It also does not mean, that a person with COVID-19 must have fever. In generally, there is accepted a preventive measure to measure a body temperature, that can help to detect an infected person. The demands for body temperature measuring devices has increased. One of these devices is the thermal security cameras (TSC).

Purpose of the article: The aim of this paper is to point out the increased use of the TSC during the global pandemic of COVID-19. At the same time, it is necessary to point out the real benefits of using these devices in relation to global trend and significant economic impacts on society.

Methods: The analysis of available materials and data of the implementation of the TCS in relation to COVID-19 crisis. There are case studies elaborated on two manufacturing companies with different approaches to the implementation of preventive measures.

Findings \& Value added: Firstly, the increased demand for protecting and preventive measures have an impact on the extreme increase in prices for these technologies compared to the pre-pandemic period. Secondly, accepted protecting and safety measures, such as TSC, do not have the expected benefits in relation to COVID-19.
\end{abstract}

Keywords: global impacts; COVID-19; body temperature measurement; thermal security camera; increasing the protection of society

JEL Classification: $D 11 ; L 21 ; 119$

\footnotetext{
*Corresponding author: ladislav.maris@,fbi.uniza.sk
} 


\section{Introduction}

In 2020, a pandemic of COVID-19 [1] has started. One of the symptoms is that a person has an elevated body temperature. One of the preventive measures against the spread of COVID-19 is the body temperature measuring [2-4]. But this does not immediately mean, that person's elevated body temperature indicates the presence of COVID-19. It also does not mean, that a person with COVID-19 must have fever. In generally, there is accepted a preventive measure to measure a body temperature, that can help to detect an infected person. The demands for body temperature measuring devices has increased. One of these devices is the thermal security cameras, that works on infra red principles, known as fever cameras $[5,6]$.

\section{Application of thermal cameras in daily life}

During the pandemic of the new coronavirus, various technical or organizational (regime) measures are implemented in many workplaces, schools or public places, which are becoming common in everyday life, especially plastic separators, masks and hand disinfectants. Body temperature control is one of the methods of reducing the spread of coronavirus [7]. We can encounter the measurement of body temperature at the entrances to buildings where these devices are installed.

In addition to these common measures, we may encounter a less common technique: temperature screening cameras, known as thermal cameras [8]. The main problem is that this technology is applied without testing.

Many companies have been buying fever cameras in the recent period of the ongoing corona crisis, believing that it will help them identify fever or, in the event of a total misunderstanding, identify a sick person for the coronavirus. Buyers are often tempted to a marketing demonstration in which these systems "reliably" measure the body temperature of multiple people at the same time, creating the false impression that they will detect infected people. Or that undetected people are negative for the presence of a new coronavirus

Another serious problem with these systems is that fever cameras do not detect infected people.

\subsection{The Booming Coronavirus Fever Camera Market}

In the last months of the pandemic, considerable funds have been spent on the purchase of fever cameras, for example, various financial support schemes (funds) in the state administration are used in the hope of helping to reduce the spread of the virus $[9,10]$.

The fever cameras market may be worth more than $\$ 1$ billion in 2020 and is by far the fastest growing market segment in the camera industry [11]. Companies that produce security [12-15] cameras can report a profit on the product portfolio of thermal imaging cameras this year, and conversely, those companies that do not offer these products but only "standard" security cameras without the mentioned line can lose this potential market share $[16,17]$.

On the part of buyers, the interest in these systems has increased, because they are equally interested in the return of employees to companies, children to schools, customers to shops, etc. If they increase people's confidence in their return, they also do not hesitate to resort to these relatively expensive systems, given the great economic losses they incur. One way to build such trust is to try to identify people with a high temperature. Due to the fact that in the time before the COVID-19 pandemic, it was uneconomical for some companies to pay several thousand euros for such a system, at present, with large economic 
losses in companies, these costs can be considered an investment in the future [18-20]. Companies that have had a real interest in these systems in the past for various reasons have expanded to include companies interested in returning people to their operations.

The examples of the increase in sales of fever cameras in the pandemic period captured in selected news sites:

- FLIR company has seen "exponential increase in demand" and is "having to prioritize hospitals and medical facilities", Reuters reported [21].

- The Israeli company Opgal modified a thermal camera used in industrial maintenance work to control high temperatures. The company has sold 1,000 cameras in the last two months - more than the previous camera since its launch in 2013 [21].

- Shares of company Flir, a manufacturer of thermal imaging systems, are rising, boosting the industry's prospects after Reuters reported on Amazon.com Inc.'s plans. use thermal imaging cameras in operations ... [22].

- Mobotix announced to the IPVM portal that sales of thermal imaging cameras increased by 175\% year-on-year in April 2020 and "well above 300\%" in May 2020 due to agreements with government institutions, hospitals, educational institutions and retailers [17].

- $\quad$ By the IPVM, Over $\$ 1$ billion in annual sales is feasible just considering 3 large manufacturers - Dahua, FLIR and Hikvision. Each company can easily sell thousands of units a month. Indeed, the issue right now is simply manufacturing enough units. At 5,000 units per company per month, at even \$7,000 average sales price, over a year that is $\$ 1+$ billion in sales [17].

\subsection{Major limitations of Fever Cameras}

Misleading advertisements from fever cameras give the impression that they detect fever in a variety of conditions. This raises false expectations among buyers. In fact, the accurate measurement of body temperature depends on the measurement of the temperature on the warmest part of the face (the corner of the eye), which can be covered by e.g. glasses, cap, sagging hair, etc. Elsewhere on the face, the temperature is colder, so values that do not capture this small area hide the actual temperature measured and lead to incorrect results. The measurement of the temperature in the middle of the forehead is a bit colder, so several manufacturers of these systems compensate the measured temperature to a more normal temperature. But it doesn't have to be just for that reason. For example, when the maximum human temperature is measured at $32^{\circ} \mathrm{C}$, the algorithm adds 4 degrees and reports $36^{\circ} \mathrm{C}$, but at $34^{\circ} \mathrm{C}$, the algorithm adds only 2 degrees and reports $36^{\circ} \mathrm{C}$. This is quite reasonable, but also misleading and dangerous .

These algorithms correctly assume that most people have a normal body temperature, so they increase low temperatures to more normal ones. And since a minimum of people have a fever at a given time, it is highly likely that the system will not report a fever even if the result is "manipulated." This is therefore dangerous, because if the system is to measure the temperature incorrectly, it creates the wrong feeling of safety. The risk of these algorithms is also undetected fever, which can be caused by temperature correction. The system can thus "correct" the measured values to "more normal" and it may happen that a subject with a temperature of $37.5^{\circ} \mathrm{C}$ could have a reported measurement result of only $36.5^{\circ} \mathrm{C}$. Another problem with these systems is that they display the temperature at any the identified face they are capturing - which can be just a photo, for example. Because the person may have the upper part of the face covered, an incorrect algorithm evaluates the measured body temperature from the lower part of the face (where the temperature is colder). These errors are also indicated by the fever cameras performed. 
For example, during the testing of more than 2 dozen fever detection devices, it was found that most Chinese systems exhibit one or more of the above-mentioned problems because they cannot accurately detect slightly elevated temperatures [7].

\section{COVID 19 and large companies survey}

In September 2020, we carried out research at the University of Žilina in Žilina - Slovakia, the aim of which was to examine the purchase of technologies and the amount of costs in Slovak manufacturing companies with more than 500 employees. Questionnaires were sent to 30 selected companies requesting completion. The questions focused on the technical measures they had taken to mitigate the spread of the new coronavirus. At the same time, we asked them about the cost item of these measures taken. We did not ask them about the lost profit or the dismissal of employees, which was related to the suspension, respectively. by slowing down supplier-customer relations. We publish the results in accordance with the anonymous principle, which we declared in the questionnaire. We have also provided companies with a company name for better identification. We do not publish names from the above-mentioned principle.

\subsection{Addressed companies}

30 companies with a criterion of more than 500 employees, based in Slovakia, were contacted. The return rate of the questionnaires was $36.6 \%$ - ie 11 questionnaires (companies). The number of employees is divided in these companies as follows: 1 company $(9.1 \%)$ states the number of employees between 501 and 1000 employees, 7 companies $(63.6 \%)$ between 1001 and 2000, 2 companies $(18.2 \%)$ between 3001 and 4000 employees and 1 company (9.1\%) state the number of employees over 5000 employees.

\subsection{Technical measures taken by companies}

Of the 11 manufacturing companies with more than 500 employees in the period since the emergency (March 2020 to September 2020), up to 6 companies have invested in the purchase of fever cameras $-54.5 \%$ of the companies surveyed. The companies also invested in the purchase of gloves $-81.8 \%$, masks - $100 \%$, hand-held non-contact thermometers $81.8 \%$, disinfectants - $100 \%$, the purchase of various barriers to guide the movement / distance of employees, especially in the so-called. areas of first contact (eg entrances, entrances, gatehouses) $-27.3 \%$, costs for testing employees, e.g. speed tests, PCR tests $90.9 \%$, installation of plexiglass $-81.8 \%$, installation of information boards or screens in order to inform about current regulations of the company in relation to the current situation $-90.9 \%$.

In addition to these technical measures, the addressed companies adopted several dozen organizational-regime measures, the most common of which are bans on visits and bans on business trips - 54.5\%, cancellation of various events / meetings - $63.6 \%$, observance of distances if the type of work allows $-90.9 \%$, random temperature measurement $-18.2 \%$, increased disinfection of hands $-100 \%$ and premises $-63.6 \%$, wearing masks $-100 \%$, measures when eating out - 90.9\%, behavior when entering / entering suppliers and customers $-90.9 \%$ or filling out forms about infectivity $-90.9 \%$. 


\subsection{Funds spent on technical measures}

We asked about the cost item as follows: Calculate the one-time costs of the technical measures taken and the regular costs per month. We remind you that we were not interested in the loss of turnover, resp. profit of the company for the past period, e.g. compared to 2019 resp. plan for 2020. In the following tables we present an overview of one-off costs (Table 1) and monthly costs (Table 2) for the adopted technical measures against the spread of coronavirus in the surveyed companies.

Table 1. One - off costs for technical measures

\begin{tabular}{|c|c|c|c|c|c|c|c|}
\hline Costs x $1000[€]$ & $1-5$ & $6-10$ & $11-20$ & $21-30$ & $31-40$ & $50-75$ & $>500$ \\
\hline N. of companies & 1 & 2 & 1 & 1 & 1 & 4 & 1 \\
\hline
\end{tabular}

From the obtained data we state that on average companies invested one-off amounts in these technical measures in a wider interval, which may be due to differently perceived costs of technical measures, other measures taken and different size of companies.

Table 2. Monthly costs for technical measures

\begin{tabular}{|c|c|c|c|c|c|}
\hline Costs $[€]$ & $101-200$ & $201-500$ & $501-1.000$ & $1.000-5.000$ & $>5.000$ \\
\hline N. of companies & 1 & 3 & 1 & 3 & 3 \\
\hline
\end{tabular}

\subsection{Recommendations from practice}

We asked about the experiences that technicians perceive as the best against the spread of coronavirus in their societies. The most common responses were: keeping distances, wearing masks and gloves, installing hand disinfectant dispensers at various locations in companies - especially where there is increased movement of people, measuring the temperature with a hand-held non-contact thermometer, shaking hand bans, increasing personal hygiene in sanitary facilities, increased disinfection of premises, regular inspection of set technical and organizational - regime measures, adjustment of entry / entrance to the company premises, regulation of work at home (home office). Only one company cited the purchase of thermal imaging cameras as a benefit.

Most companies consider the adoption of technical measures to be beneficial, as they create space for the adoption of organizational and regime measures (masks, distances, disinfection).

\subsection{Detected positive cases of coronavirus}

At the end of the questionnaire, we asked if the companies recorded a positive case of their own employee for a new coronavirus. The above answers show that only 2 companies did not have a positive case for coronavirus $-18.2 \%$. The other 9 companies $-81.8 \%$ report the number of positive cases up to 5 people. No company recorded over 5 positive cases by September 2020. 


\subsection{Comparison of 2 companies with different approaches to fever cameras}

We compared the data of 2 manufacturing companies with a similar focus and number of employees. We name companies with the letter attributes A and B in order to maintain the anonymous principle that we declared in the survey.

Table 3. The comparison of 2 automotive companies

\begin{tabular}{|c|c|c|}
\hline Comparison criterion & COMPANY A & COMPANY B \\
\hline Number of employees & 4.000 & 4.200 \\
\hline Production area & automotive & automotive \\
\hline Gloves, masks, disinfection & yes & yes \\
\hline Handheld thermometers & yes & yes \\
\hline Thermal imaging cameras & YES & NO \\
\hline Barriers, plexiglass & yes & yes \\
\hline Coronavirus testing & YES & NO \\
\hline Affidavits of no infectivity & yes & yes \\
\hline Disinfection of premises & yes & yes \\
\hline One - off costs & over $50,000 €$ & over $50,000 €$ \\
\hline Monthly costs & over $5,000 €$ & over $5,000 €$ \\
\hline $\begin{array}{l}\text { The best evaluated measures by the } \\
\text { company }\end{array}$ & Masks - Distance - Hands & Disinfection dispensers \\
\hline Number of infected employees & 1 & 2 \\
\hline
\end{tabular}

As we can see in Table 3, Company A with a positive attitude and Company B with a negative attitude to purchase thermal imaging cameras incur comparable costs for comparable technical measures. Company A reimburses testing on COVID-19 for a group of people who have come into contact with an infected person. Company B does not reimburse these costs. Company A had 1 person with confirmed coronavirus and company $\mathrm{B}$ had identified 2 people for coronavirus.

Other organizational and technical measures are very similar (purchase of masks, gloves, disinfection of premises, disinfection stands for hands, etc.). All the measures taken seem logical with a high success rate in the fight against the spread of the disease. The two companies being compared have crisis staffs in place and different contingency plans to reduce the resulting economic losses while ensuring the protection of their employees.

The difference in the cost item is e.g. at different prices for purchases in different numbers of employees or the area of the premises to be disinfected or different density of distribution of disinfection stands. 
Company A stated that the technical measures taken served exclusively to fulfill organizational measures and increase employees' sense of security. In company B, they assessed that they would not incur the cost of fever cameras because they considered it unnecessary and preferred to invest in increased disinfection of premises as well as the purchase of separators for the separation of persons in the first contact (gatehouse) and other less costly measures.

The difference in the number of infected people is negligible if we look at the total number of employees in both companies.

\section{Discusion}

It is certainly not our goal to dishonor thermal imaging cameras, which have their place in the industry. Our aim was to analyze the contribution of thermal imaging cameras in the pandemic period of the new coronavirus in relation to the measurement of body temperature. An important aspect in this area is played by the realistically achievable goal of implementing these cameras, and that is the detection of high temperature (fever) as one of the symptoms of this viral disease. The problem, however, is that fever automatically means the disease, but basically means the person's unhealthy condition. Which is basically the right approach and it may not matter what the cause of the fever.

The technical and organizational measures taken in companies should be logically linked. In the coronavirus period, they manifest themselves as essential regime measures, namely the wearing of masks, increased personal hygiene and protection, the caution of individuals and the responsible attitude of employees in the workplace.

The question remains how high-quality thermal imaging systems are and what real contribution they make to detecting people with high temperatures in relation to the conditions in which they are placed.

\section{Conclusion}

Many thermal imaging camera manufacturers program their algorithms to dynamically adjust the measured temperature to a "more normal" result. However, this increases the risk of absenteeism of people and creates a false sense of security. Almost every person is assigned a "normal" temperature, even if a problem characteristic (property) is perceived, which fundamentally negatively affects the temperature measurement - e.g. glasses, cap, long hair in the forehead area, fast walking, group measurement in motion, inappropriate scanning angles to the device, etc.

Due to the growing trend of procuring thermal imaging cameras for fever detection, we can assume the presence of these systems in the immediate vicinity. With the gradual decline in the continuing interest in these devices, the decline in prices for these devices will also come into play, which may have a positive impact on potential buyers. We also anticipate that increased interest in these technologies will lead to technical improvements in fever cameras and may be a common feature in hospitals, schools, shops, workplaces or other institutions in the future to prevent infection in the event of a communicable disease.

Our interest was to find out the current state of implementation in selected companies. The survey showed that in large companies with more than 500 employees, thermal imaging cameras were implemented in $54.5 \%$ of cases in the coronavirus period, and thus we see clear evidence of increased interest in these systems.

This paper was supported by project VEGA 1/0768/19" 


\section{References}

1. Mehra, M. R., Desai, S. S., Kuy, S., Henry, T. D., Patel, A. N. (2020). Cardiovascular Disease, Drug Therapy, and Mortality in Covid-19. New England Journal of Medicine, 382(25), 2582-2582.

2. Xie, J. G., Zhu, Y. J. (2020). Association between ambient temperature and COVID-19 infection in 122 cities from China. Science of The Total Environment, 724, 3820138201.

3. Lai, T. H. T., Tang, E. W. H., Chau, S. K. Y., Fung, K. S. C., Li, K. K. W. (2020). Stepping up infection control measures in ophthalmology during the novel coronavirus outbreak: an experience from Hong Kong, Graefes Archive for Clinical and Experimental Ophthalmology, 258(5), 1049-1055.

4. Adhikari, S. P., Meng, S., Wu, Y. J., Mao, Y. P., Ye, R. X., Wang, Q. Z., Sun, C., Sylvia, S., Rozelle, S., Raat, H., Zhou, H. (2020). Epidemiology, causes, clinical manifestation and diagnosis, prevention and control of coronavirus disease (COVID19) during the early outbreak period: a scoping review. Infectious Diseases of Poverty, 9(1), 29-29.

5. Nguyen, A. V., Cohen, N. J., Lipman, H., Brown, C. M., Molinari, NA. A., Jackson, W. L., Kirking, H., Szymanowski, P., Wilson, T. W., Salhi, B. A., Roberts, R. R., Stryker, D. W., Fishbein, D. B. (2010). Comparison of 3 Infrared Thermal Detection Systems and Self-Report for Mass Fever Screening. Emerging Infectious Diseases, 16(11), 1710-1717.

6. Bardou, M., Seng, P., Meddeb, L., Gaudart, J., Honnorat, E., Stein, A. (2017). Modern approach to infectious disease management using infrared thermal camera scanning for fever in healthcare settings. Journal of Infection, 74(1), 95-97.

7. Honovich J. (2020, Jul 5). 24 "Fever" / Temperature Screening Devices Test List. IPVM - IP Video Market Info. Retrieved from: https://ipvm.com/forums/videosurveillance/topics/18-fever-temperature-screening-devices-tested

8. Bendix, A. (2020, June 17). US states are instituting temperature checks at offices and restaurants, but a quarter of coronavirus patients don't develop a fever. Business inside. Retrieved from: https://www.businessinsider.com/temperature-checks-flawedcoronavirus-cases-asymptomatic-no-fever-2020-5

9. Vel'as, A., Kutaj, M., Durovec, M. (2017). Influence of changing the parameters of the camera system on video-based motion detection. In. J. Ortega-Garcia, A. Morales, J. Fierrez, R. Vera-Rodriguez, R. Lazzeretti (Eds.), Proceedings - International Carnahan Conference on Security Technology (pp. 1-5). Spain-Madrid.

10. Glaser, A., Solon, O. (2020, September 16). As schools spend big on temperature check tech, experts warn: It won't work. NBCUniversal300. Retrieved from: https://www.nbcnews.com/tech/tech-news/schools-spend-big-temperature-check-techexperts-warn-they-won-n1240246

11. Anne-Françoise, P. (2020, June 2). COVID-19 Triggers a Market Boom for Thermal Technologies. EET ASIA. Retrieved from: https://www.eetasia.com/covid-19-triggersa-market-boom-for-thermal-technologies/

12. Soltes, V., Stofko, S. (2015). The impact of population movement on security in the age of globalization. In T. Kliestik (Eds.), Globalization and its socio-economic consequences, pts I and II: Proceedings of 15th International Scientific Conference on Globalization and its Socio-Economic Consequences (pp. 773-778). Rajecke Teplice: Proceedings Paper. 
13. Soltes, V., Stofkova, Z. (2016). Security as an aspect of the quality management in local self-government in age of globalization. In T. Kliestik (Eds.), Globalization and its socio-economic consequences, 16th international scientific conference proceedings, pts I-V: 16th International Scientific Conference on Globalization and its SocioEconomic Consequences (pp. 2060-2067). Rajecke Teplice: Proceedings Paper.

14. Hofreiter, L., Zvakova, Z. (2017). Theoretical Aspects of Critical Infrastructure Protection. In A. Kravcov, E. B. Cherepetskaya, V. Pospichal (Eds.), International Conference on Durability of Critical Infrastructure, Monitoring and Testing (ICDCF) (pp. 139-147). Czech Republic: Proceedings Paper.

15. Kubas, J., Vel'as, A., Siser, A. (2017). Implementation of Multi-criterias Decision Making as the Method Used to Achieve Optimal Level of Security in Local Municipalities. In H. Zhang (Eds.), 4th icmibi international conference on training, education, and management (ICMIBI-TEM 2017) (pp 371-375). U Arab Emirates Proceedings Paper.

16. Boros, M., Kutaj, M., Maris, L., Vel'as, A. (2018). Development of security at the local level through practical students training, In L. G. Chova, A. L. Martinez, I. C. Torres (Eds.), 12th International Technology, Education and Development Conference (INTED) (pp 725-729). Spain: Proceedings Paper.

17. Honovich, J., Rollet Ch. (2020, April 21). The Booming Multi-Billion Coronavirus Fever Camera Market. IPVM - IP Video Market Info. Retrieved from: https://ipvm.com/reports/corona-cam-market

18. Kampova, K., Makka, K., Zvarikova, K. (2019). Cost benefit analysis within organization security management. In T. Kliestik (Eds.), 19th international scientific conference globalization and its socio-economic consequences 2019 - sustainability in the global-knowledge economy. Rajecke Teplice:EHS Conference .

19. Hudakova, M., Masar, M., Buganova, K. (2018). Assessment of the financial risks of the small and medium-sized enterprises in Slovakia, In A. Maloletko, N. Rupcic, Z. Baracskai (Eds.), Economic and social developmen: 34th International Scientific Conference on Economic and Social Development (pp. 505-2013). Moscow: Proceedings Paper.

20. Buganova, K., Hudakova, M., Masar, M. (2018). Market risk analysis in terms of impact on entrepreneurial activity of small and medium-sized enterprises in Slovakia, In A. Maloletko, N. Rupcic, Z. Baracskai (Eds.), Economic and social development: 34th International Scientific Conference on Economic and Social Development / 18th International Social Congress (ISC), (pp 402-410). Moscow: Proceedings Paper.

21. Nellis S. (2020, April 9). FOCUS-As fever checks become the norm in coronavirus era, demand for thermal cameras soars. Thomson Reuters. Retrieved from: https://www.reuters.com/article/health-coronavirus-thermal-cameras/focus-as-feverchecks-become-the-norm-in-coronavirus-era-demand-for-thermal-cameras-soarsidUSL1N2BR31H

22. Ludlow, E. (2020, April 20). Rush for Thermal Cameras Boosts Flir Before Factories Reopen. Bloomberg L.P., Retrieved from: https://www.bloomberg.com/news/articles/2020-04-20/rush-for-thermal-camerasboosts-flir-before-factories-reopen 